\title{
Evaluating the decision-making on a Public-Private Partnership to finance a road project in Vietnam
}

\author{
Dinh Thi Thuy Hang \\ Ritsumeikan Asia Pacific University \\ Japan \\ Thitdi14@apu.ac.jp
}

\begin{abstract}
Public-private partnership (PPP) has become a significant alternative to traditional procurement in improving public projects in many countries since the 1990s. Along with the development of PPP projects, value for money (VFM) assessment is considered as an effective tool to support PPP decision-making process, which is widely used by many governments. Like several countries, Vietnam has applied PPP to develop road transport infrastructure. However, the government of Vietnam has never conducted VFM assessment to determine whether using PPP instead of a conventional delivery is better choice to finance a proposed project. This paper proposes application of the value for money assessment to evaluate the suitability of PPP model for a given project. A case study of My Loi project in Vietnam is used to examine the viability of the method. The results of the research using Monte Carlo simulation methodology demonstrate that there is a 23.4 percent chance that PPP could be a good candidate to implement the My Loi project. Sensitivity analysis reveals that the outcome of VFM is the most sensitive to the toll of Public sector comparator (PSC) and the least sensitive to inflation.
\end{abstract}

Key words: Public-Private Partnership (PPP), value for money (VFM), Monte Carlo simulation (MCs), Public sector comparator (PSC), Vietnam

JEL classification: L32, L33

\section{INTRODUCTION}

One of the most serious problems Vietnam is facing today is the road system. It is suffering from increasing demand while the quality of roads is decreasing. According to the General Statistic Office of Vietnam (2016), the volume of road transport passengers in 2001 was more than 500 million, this figure has increased rapidly during the past decade and almost peaked 3 bln passengers in 2013. On the other hand, according to the Global Competitiveness Report (2015), the quality of roads in Vietnam ranks $104^{\text {th }}$ out of 144 countries in the world. "Given high and rapidly increasing demand for infrastructure services, and expectations of lower levels of ODA in the near future, mobilizing private sector investment is necessary to fill the financing gap. In this sense, PPPs are recognized as one of the most effective ways of financing 
infrastructure development" (World Bank, 2013). "Using a public-private partnership could increase the money available for highway projects and complete the work more quickly or at a lower cost than is possible through the traditional method. Specifically, such a partnership could secure financing for a project through private sources that might require more accountability and could assign greater responsibility to private firms for carrying out the work" (Kile, 2014).

The issue is posed whether decision-making to pursue PPP instead of a conventional delivery is a good choice for financing this project. How to evaluate this decision-making?

According to D. Morallos and Amekudzi (2008), "value for money is one of the leading tools available to public managers to assess the value of pursuing a project through a public-private partnership versus traditional procurement". In a similar way, C.O. Cruz and R.C. Marques (2013) advocated that "PPPs or traditional procurement arrangements are possible alternatives to provide that same output. Because decision makers have different models to ensure the provisions of the infrastructure and/or service, it is necessary to compare both models and select the best one". The National Council for Public-Private Partnerships (2012) claimed that "one way of assessing the potential benefits associated with a PPP is through VFM analysis, which compares the cost of PPP-based provision to that of traditional projects delivery, providing decision makers with a quantitative tool and data to help them make the case for selecting the most appropriate mode of project delivery".

There has been more than 23 years since Vietnamese government firstly stimulated private participation to invest in road projects. Since then, Vietnam has witnessed an increase in the number of PPP projects, which contribute to reducing state budget burden as well as develop economics in the country. For example, 62 road projects have been implemented under PPP model with the total investment of VND186,600 billion. However, according to Deloitte (2015), such the increase in PPP projects does not mean that PPP is always the most suitable choice. In fact, some PPP road projects in Vietnam are facing failures and thus there are debates on the selection of the best option. One of such projects is My Loi Bridge. Some experts in this field believed that PPP model is suitable for this project. On the other hand, others confirmed that conventional delivery is a better choice. Unfortunately, until now there has been no evidence to clarify this problem. This research applies VFM assessment to examine whether PPP or conventional delivery is better to finance this particular project.

The paper comprises of four parts, it begins with a review of VFM. In addition, the paper also concentrates on the research methodology. Then, this paper describes the characteristics and the existing problems related to the selection of the best option for the case study applied. Next, in the findings of the research, this paper discusses whether PPP could bring better value as compared with traditional delivery for this case study. Finally, limitation of this research is mentioned, the major shortcoming of this research is the lack of analysis from the qualitative viewpoint. In order to deal with this limitation, suggestions for future work is provided. 


\section{LITERATURE REVIEW}

\section{Definitions of VFM}

Contreras (2014) claimed that "VFM is the optimum combination of whole-of-life costs and quality to meet requirement, which does not always mean choosing the lowest cost bid. VFM not only measures the cost, but also takes into account the quality and fitness for purposes, in determining whether goods and services represent good value". Zhen Hu and Shu Chen (2014) found that "Value for money (VFM) is a good measure of the performance of PPP projects, which represents the philosophy of the public sector in partnering with the private sector in delivering public works and services through contract-based PPPs". Once again, Takim, R., et al (2009) confirmed that "VFM is not the lowest cost option but an understanding of the whole life benefits and appropriate risk allocation between public and private sectors". Generally, although there are many different definitions of the term "value for money", most scholars agree that value for money is a combination of both quantitative and qualitative assessment in order to determine whether a PPP will save money and bring more efficiency for public sector compared to a conventional procurement to finance a particular project. Sarmanto, (2010) advocated that "there are usually two components of value for money: a quantitative one (including all factors can be measured by the public sector comparator), and a qualitative one (aspects that cannot be quantified)". It is clearly now, theoretically, in order to have a comprehensive assessment, one should conduct both quantitative and qualitative approaches. However, in fact, quantitative VFM has been more popular and widely adopted in PPP decision-making process in many countries compared to the qualitative one. This is because that this approach is more transparent and confident. In particular, quantitative assessment is based on economic indicators, which can be quantified. Thus, it allows us to know exactly the estimated costs of a proposed PPP project with those of conventional delivery. Meanwhile, qualitative analysis is usually based on the subjective opinions of stakeholders, which could not measure the value of advantages of PPP model compared with the traditional procurement.

In terms of quantitative VFM, World Bank (2013) defined quantitative VFM as "involves comparing the value for money of a proposed PPP (or actual bids received) with a "Public Sector Comparator" (PSC) - that is, a model of the project if implemented through traditional public procurement". Likewise, according to D. Morallos and Amekudzi (2008) "the quantitative VFM component includes all project factors that can be valued in monetary terms. It features a methodology that compares the PPP bid with a hypothetical scenario called the public-sector comparator (PSC)". Additionally, Tsukada (2015) point out that quantitative VFM is "used to determine in advance how much money the government would eventually pay to the private sector as compared with a publicly provided project". Moreover, D. Tsamboulas et al. (2013) confirmed that quantitative VFM "is used to compare the required public funds for two cases: the first case refers to the implementation of the project with PPP, while the second case to the delivery of the project by public sector". 


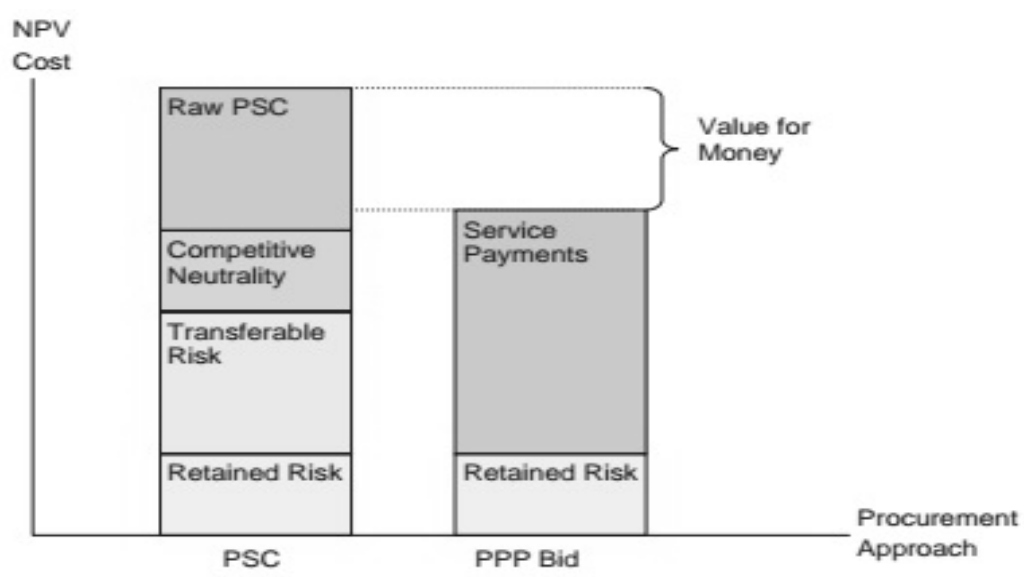

Figure 1: Comparing between PSC and PPP bids

Source: D. Marollas et al. (2009).

As can be seen in Figure 1, PSC represents the cost of a project carried out by the public sector, which includes raw PSC, competitive neutrality, transferable risk and retained risk. Meanwhile, PPP bid represents the cost of a project if conducted under a PPP, which combines retained risk and service payments. If VFM is larger than zero, a project should be administrated by private sectors. Otherwise, the project should be incurred by public sector.

\section{METHODOLOGY}

The research develops Monte Carlo simulation (MCs) to summarize the simulation of the VFM output. In addition, an application of sensitivity analysis helps to identify and compute effects of the uncertain input variables on decision-making to pursue PPP model. There are four stages conducted in the simulation model of this research: (1) Determination of input variables (2) Identification of distributions for the input variables and running the simulation for them (3) Estimation of cash flow of the PSC and PPP bid (4) Generating distribution of the VFM output (see Figure 2). 


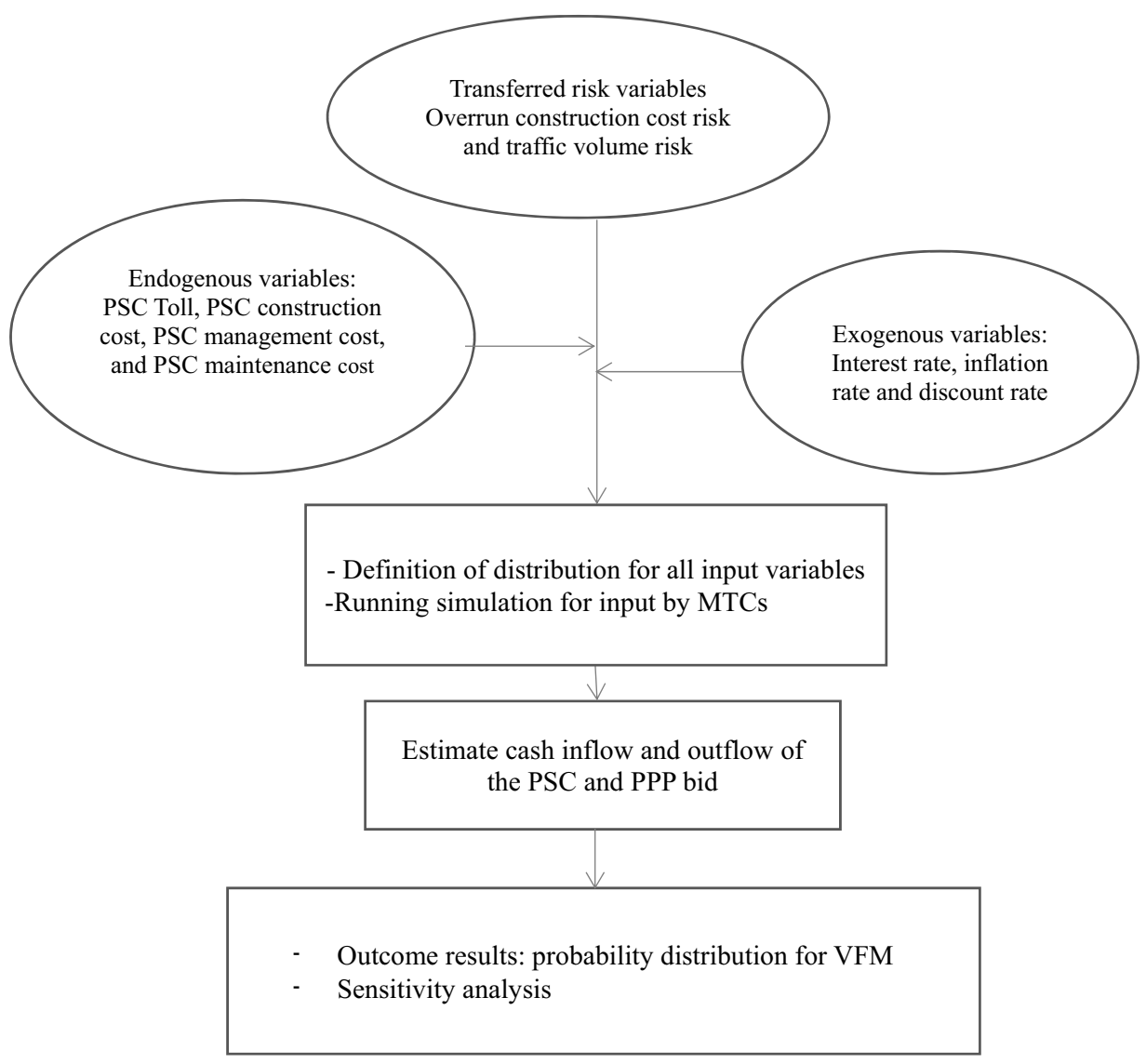

Figure 2: Flowchart of methodological research

\section{Step 1: Determination of input variables}

The model in this research consists of three main kinds of input variables, namely (1) transferred risk variables (2) endogenous variables, and (3) exogenous variables.

\section{Transferred risk variables}

Transferred risks means "risks are changed from public sector to the selected private investors" (Infrastructure Ontario, 2007). In other words, if the project is conducted under PPP, the value of risks cost that is expected to be transferred to the private sector. In this research, transferred risk variables are associated with the construction and traffic volume risk. 


\section{Endogenous variables}

The construction cost, maintenance cost, management cost and toll rates are decided during negotiation process before contract is awarded. They are decision variables or called endogenous variables. The general management cost comprises of three components, including the periodic maintenance cost, special maintenance cost and upgrade cost.

\section{Exogenous variables}

The interest rate of government bond, and discount rate for cash flow of PSC mentioned in the case study is defined as exogenous variables for the simulation model. This is because these variables depend on the country's economy. Regarding the interest rate of government bond, this research uses actual data of interest rate of fifteen-year government bond in Vietnam during the period from 2005 to 2015. With respect the discount rate, this research uses risk-free rate.

On the other hand, according to Malini, (1997), "developed economies strive to contain their inflation rates to modest levels of $<5 \%$ per annum, while other countries suffer severe inflation of a high magnitude, reflecting a higher level of risk associated with the investment". Therefore, besides discount rate and interest rate, inflation is considered as uncertain input variable in the model. Based on the historical inflation data from 1994 to 2015 in Vietnam, we forecast time series of inflation in the future using @ Risk software version 7.5 , as followings chart:

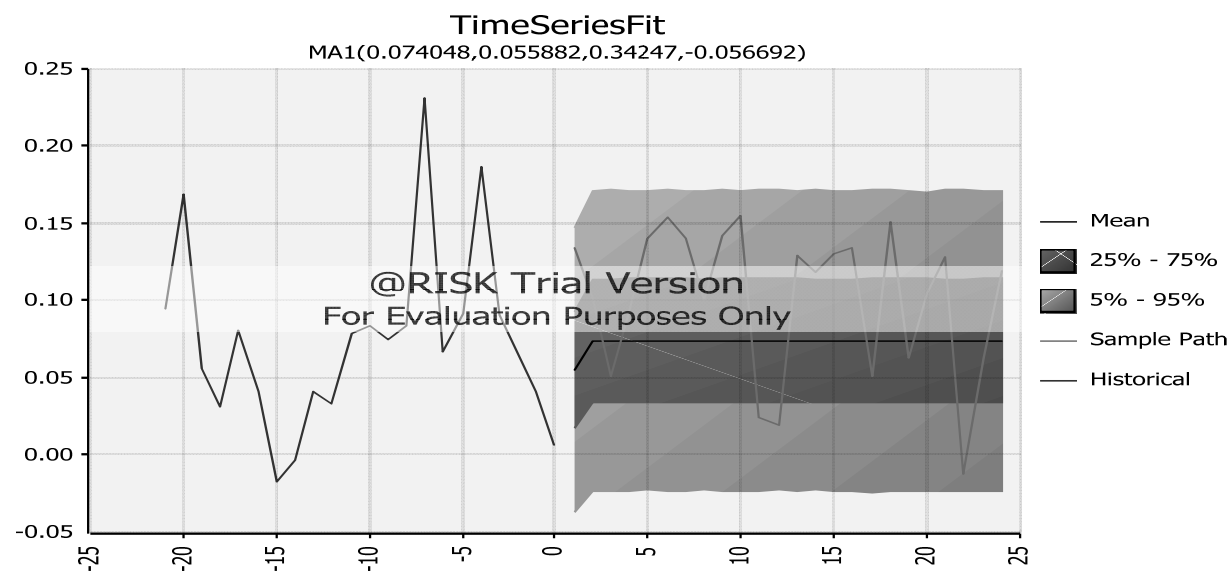

Figure 3: Time series of inflation rate

Source: Analyzed by author.

The Y-axis characterizes the inflation rate, and the X-axis represents the past time and future time compared to the base year (the year 2016). As shown in the figure, the green path illustrated the inflation rate in Vietnam during the historical period (from 1994 to 2015), and the red line represents the forecasted inflation rate in the future. 


\section{Step 2: Definition of probability distribution for all input variables}

Identifying the probability distribution of input variables is very important in the application of Monte Carlo simulation. According to Park K. A., (2007), "if there are proper historical observations, the probabilistic distribution can be defined from these data, while if these are absent then this distribution can be assumed by personal or organizational intuitions and decisions". Likewise, C.O. Cruz and R.C. Marques (2012) emphasized that "definition of distributions for cost components should be based on historical data or experts' judgment." Furthermore, according to F. Belaid and D. De Wolf (2009), standard statistical distribution such as normal, the log-normal, the uniform and triangular distributions are often used to describe the input parameters.

To run MCs simulation, each variable is assigned the best probability distribution. However, for the transferred risk and exogenous variables, the available data is not sufficient to determine the distribution. Hence, Bootstrap method is applied to respond to this issue. Alternatively, regarding the endogenous variables, due to lack of relevant data, the probability distribution for these variables is determined subjectively from the previous studies.

\section{Step 3: Estimation of cash flows of PSC and PPP bid}

For the transferred risk and is determined based on the historical version 7.5. Besides toll, inflow of SBP could achieve from subsidy from the government. Additionally, cash outflow of the PSC as well as the PPP is calculated based on the construction cost during the years of construction, maintenance cost, management cost during the operation phase, and financing cost during the concession period.

\section{Step 4: Simulation Output of VFM}

The simulation output of the model is net present value of the VFM, which is in the form of stochastic variables related to probability distributions. The result of the simulations provides the likelihood of the VFM being positive or negative. Apart from this, advanced sensitivity analysis facilities to evaluate how input variables have impact on the VFM when there is interaction of other variables in the model.

\section{CASE STUDY}

My Loi Bridge is a project that was initially designed to be carried out under public sector procurement. The building of the project started in 2009 by the government direct investment. The original investment capital of VND 1,438 billion was funded by issuing government bond. According to the original plan, the project would have been finished in 2012. However, since traditional delivery was suggested to implement the project, the construction of the project was not yet completed until 2013. At that time, the Vietnamese government decided to encourage private sector to finance the My Loi Bridge. However, according to some PPP experts of Vietnam, the project could be better if implemented by public sector. The question is raised that whether the project should be conducted by the government direct investment as an original suggestion or procured by application of PPP model. 


\section{FINDINGS AND DISCUSSION}

\section{Basic assumption for assessment}

\section{* Raw cost in PSC}

In order to compute the cost of the project implemented by public sector, the capital cost items of the PSC is extracted from the feasible report of the My Loi project (including design and construction contract price, administration cost, land acquisition and contingency cost for construction). Other costs including operation cost and maintenance cost, which are not available from historical data, are estimated applying the cost estimate standard of the Vietnamese government. For example, regarding the operation cost of the PSC, annual costs are estimated by multiplying the 15 percent (regulated on the Circular 90/2004/TT-BTC of Ministry of Finance dated 2004) and the revenue of the project in the first year of operation.

\section{* Discount rates}

This research assumes that the discount rate for cash flow of PSC is risk-free rate. According to Arrow \& Lind 1 (1970) "the discount rate to be used in public investments should be the "risk-free" rate reflecting the risk-neutrality of the public sector", since "government can spread the risks among all taxpayers when it undertakes an investment" (Checherita, 2009). Otherwise, for private projects, investors mobilize capital from equity and borrowing as so the discount rate for cash flow of SBP should be weighted average cost of capital (WACC).

\section{Calculation of quantitative VFM}

Table 1

Comparison of the PSC and PPP bid

Unit: billion VND*

\begin{tabular}{|c|c|c|}
\hline Items & PSC (I) & PPP bid (II) \\
\hline Outflow (A) & $3,060.40$ & $6,597.81$ \\
\hline Inflow (B) & 997.46 & $4,808.22$ \\
\hline Net present of cash flow (A) - (B) & $2,062.94$ & $1,789.59$ \\
\hline VFM (I) - (II) & 273.35 & \\
\hline
\end{tabular}

*VND (Vietnamese Dong) $=0.00005$ USD

Source: Calculated by author.

As shown in Table 1, under PPP model, the total life cycle cost of the project is expected to be VND $6,597.81$ billion, while under traditional government procurement the cost of the project is predicted to be VND 3,060.40 billion. The comparison of the two net present costs proves a differential VFM of VND 273.35 billion in favor of the PPP scheme. Thus, PPP model is expected to be more beneficial to provide the My Loi project.

1 Cited in Grout (2003) 


\section{Monte Carlo simulation}

The variation of the VFM of the project is estimated by applying the MCs. The frequency distribution of the VFM by stochastic change of input variables (see Figure 4) is utilized to generate the project variation created as an output of the risk simulations. After running 10,000 trials, the Monte Carlo simulation results reveal that mean of VFM is VND -567.44 billion and standard deviation is VND 700 million. Further, the probability value of quantitative VFM distributes between VND -1,939 billion and VND 479 billion is $90 \%$. Additionally, as represented in figure 5 , the probability of VFM being positive is $23.4 \%$. In the other words, there is a $23.4 \%$ chance that application of PPP model to finance the project could produce better value for the government than traditional procurement. It should be mentioned that there is a difference on the result of VFM between single value estimation and the MCs. Given the result of single value calculation, the value of VFM is VND 273.35 billion (see Table 1), while based on the results of MCs the expected value of VFM is VND -567.44 billion (see Figure 4). In other words, according to the result of single value estimation, PPP scheme is more appropriate than public sector procurement. Meanwhile, according to the results of MCs, public sector procurement is more suitable than PPP model. The reason leading to this difference may be due to that the input variables estimated by single value estimation method which is different from the mean value by MCs. Especially, the toll of vehicle in the single-value estimations is VND 15,000 per PCU, while MCs creates VND 32,5000 per PCU as an expected value. Likewise, forecasted inflation rate based on the single-value estimation is $6 \%$, while the historical data creates around $7 \%$ as forecast trend. These can make quantitative VFM indicator by MCs lower, compared to the result of single value estimation method.

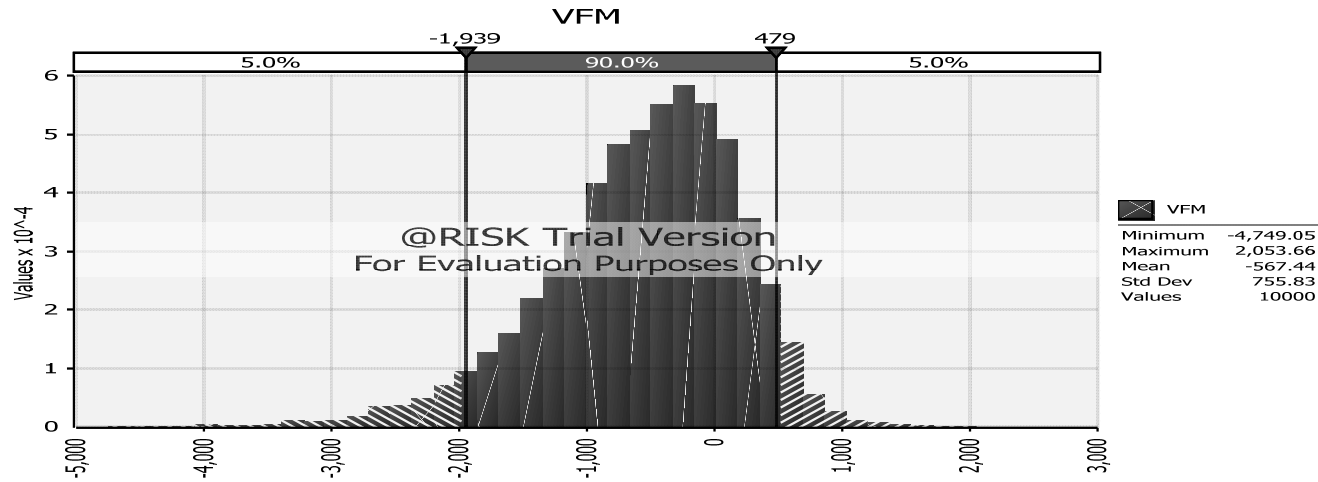

Figure 4: Distribution for the project's value for money Source: Analyzed by author. 


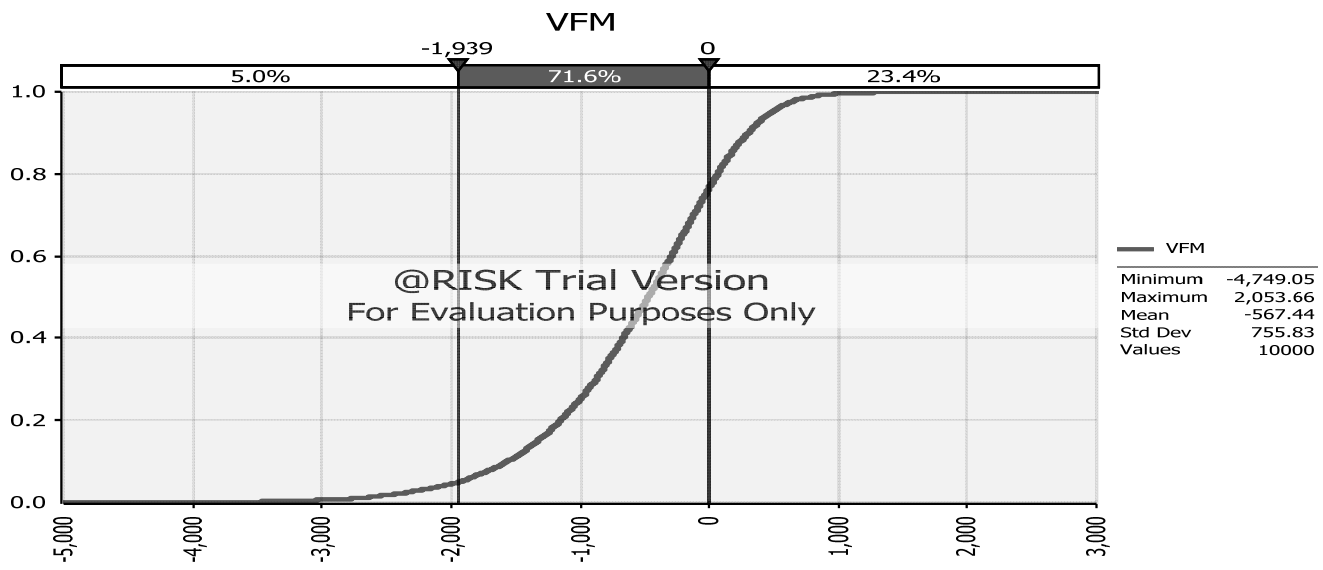

Figure 5: Accumulative probability of positive VFM

Source: Analyzed by author

\section{Summary cashflow of VFM}

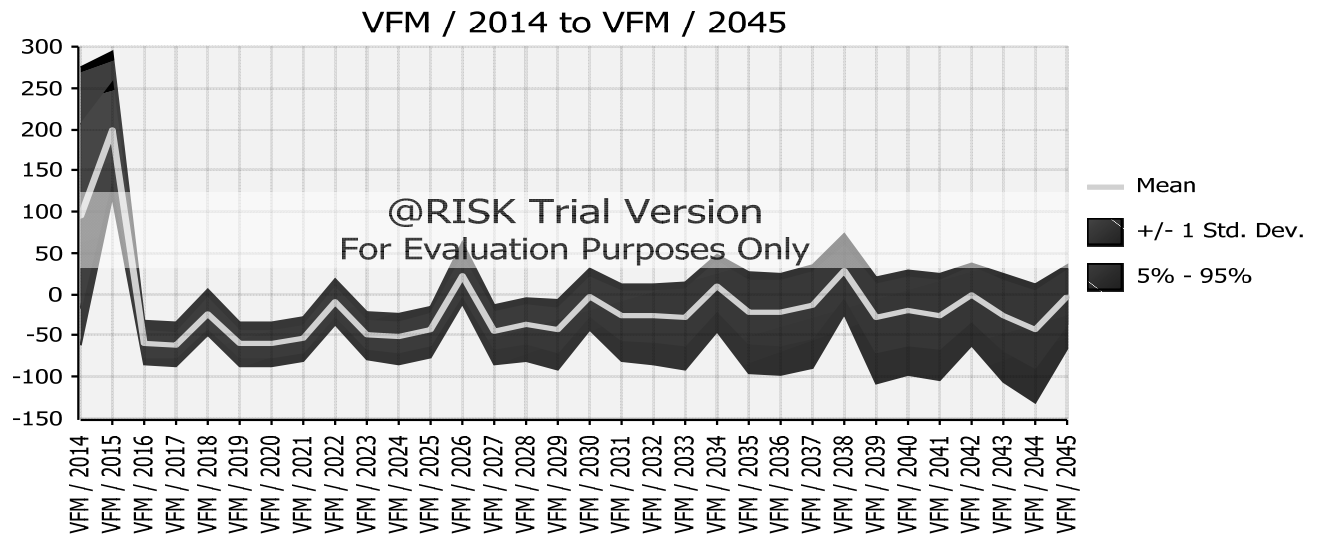

Figure 6: Summary trend of VFM between 2014 and 2045

Source: Analyzed by author.

Figure 6 summarizes the distributions generated for the value of VFM range, which helps to know how the value of VFM of the My Loi project is changed during the period from 2014 to 2045. The X-axis describes the concession term of the project from 2014 to 2045. The Y-axis represents the net present value of the VFM. As can be seen, positive VFM achieved in the first few years, however, in the subsequent years, cash flow of the VFM becomes negative. In other words, PPP model can save larger cost to the government than public sector procurement in the construction phase of the project, but public sector can do better than private sector in the operation phase. 


\section{Sensitivity analysis}

Figure 7 represents the sensitivity tornado graph of the VFM. The X-axis characterizes the variation in the outcome value. The Y-axis characterizes each input variable. The longer the bar, the more sensitivity VFM is to input variables. The critical variable has an important effect on the evaluation outcome of VFM is PSC toll, while variables with the least effect on VFM are inflation in the year 2020, 2024 and 2025. Especially, when standard deviation of toll increases +1 , the standard deviation of VFM will decrease 0.69, equivalent to VND 521.89 billion (see Figure 8). In contrast, a one standard deviation increase in inflation in the year 2020 makes VFM of the project reduce by 0.10 standard deviation, which respondents to VND 76.470 billion. It implies that in order to improve VFM, one should mostly concentrate on and adjust the toll of the PSC.

Once again, the sensitivity tornado graph confirms that the positive elements have a influence on the VFM of the project are design and construction cost in year 2014, interest rate of government bond, cost overrun risk and discount rate. This may be explained that the increases in one of these indicators leads to the increase in value of PSC, therefore, VFM raises. Meanwhile, the inputs have a negative influence in the project's VFM are inflation rate, toll and revenue risk. This is due to the rise of inflation produces the increase in PSC inflow is bigger than the PSC outflow, so it leads to the fall down in VFM. Likewise, the increases in the toll of PSC makes the cash flow of PSC reduce, leading to the decrease in VFM. It could be concluded that additional construction cost of PSC, interest rate of government bond, cost overrun risk or discount rate is likely to increase the potential viability of PPP model. Otherwise, with a lower revenue risk, inflation rate or toll is, the higher the viability of PPP model is.

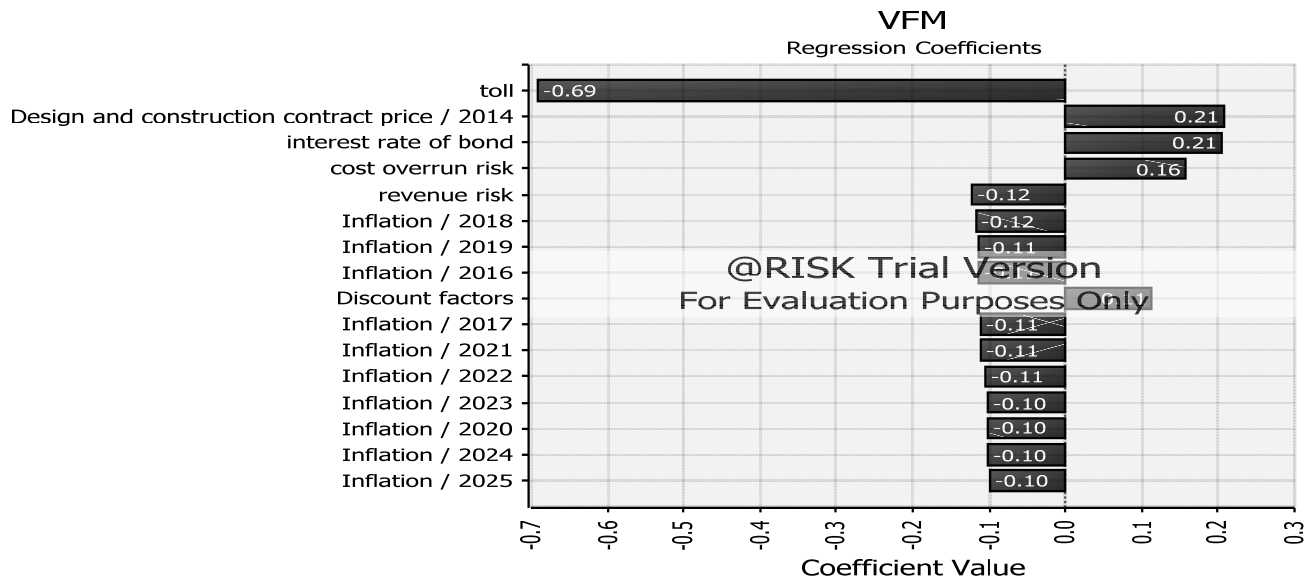

Figure 7: Sensitivity tornado graph for the project's value for money

Source: Analyzed by author. 


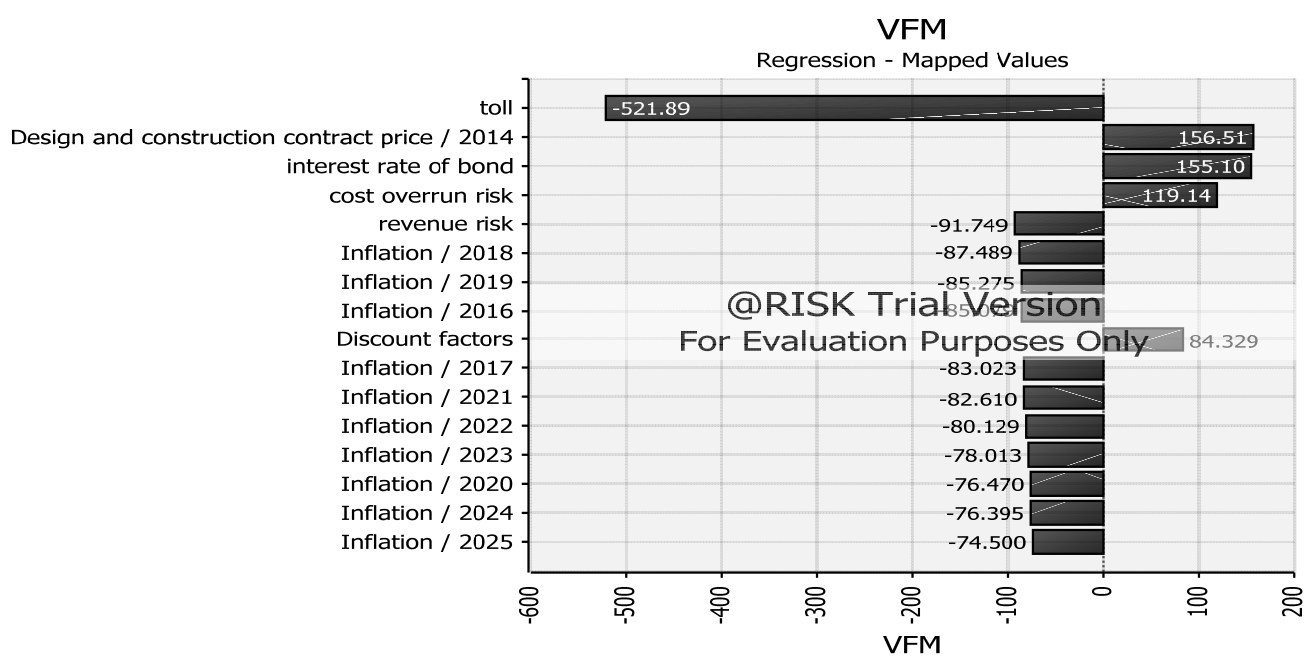

Figure 8: Sensitivity tornado diagram for the project's value for money

Source: Analyzed by author.

\section{CONCLUSION}

PPP model seems not to be a good candidate to implement the My Loi project. Especially, the results of MTCs reveal that the probability that PPP scheme is better than traditional public delivery is $23.4 \%$. It implies that the Vietnamese government's decision-making to stimulate private participation in this project may not be appropriate.

Theoretically, a PPP project plan is approved after evaluating feasibility and testing value for money. However, in the current context of Vietnam, VFM assessment of a PPP project has not considered and conducted. Thus, the paper proposed the VFM assessment for evaluating the suitability of a specific PPP project in Vietnam. This method is expected to be a path for further application in Vietnam when choosing PPP model to finance a proposed project. In addition, My Loi project is a good practiced case to explore application of the VFM assessment to select the best option between PPP model and traditional government procurement.

However, it should be mentioned that the potential limitation of this paper is lack of comprehensive evaluation of a PPP project in general. This research ignores consideration of the standpoint of qualitative PPP decision-making to procure a particular project. On the other hand, insufficient available data regarding case studies does not allow us to evaluate whether that PPP model could provide higher VFM in general road projects in this paper. However, in respond to the first issue, future works should employ Analytic Hierarchy Process. Regarding the latter, the method of Bootstrap is recommended to apply in the future research. 


\section{RERERENCES}

Australian Government. (2013, August). National Public Private Partnersip Guideline, Volume 5: Discount rate methodology guidance. Retrieved June 15, 2016, from Department of Infrastructure and Regional Development: https:// infrastructure.gov.au/infrastructure/ngpd/files/Volume-5-Discount-Rate-Guidance-Aug-2013-FA.pdf

C.O. Cruz \& R.C. Marques. (2012). Using probabilistic methods to estimate the public sector comparator. ComputerAided Civil and Infrastructure Engineering, 27(10), 782-800.

C.O. Cruz \& R.C. Marques. (2013). Infrastructure Public-Private Partnerships: Decision, Management and Development. Berlin Heidelberg: Springer.

C.O. Cruz \& R.C. Marques. (2014). Theoretical considerations on quantitative PPP viability analysis. Journal of Management in Engineering, 30(1), 122-126.

Checherita, C. D. (2009). A Macroeconomic Analysis of Investment under Public-Private Partnerships. Diss., George Mason University.

D. Morallos \& Amekudzi. (2008). A state of the practice of value for money analysis in comparing Public Private Partnership to traditional procurement. Public Works management Policy, 13(2), 114-125.

D. Tsamboulas, A. Verma, P. Moraiti. (2013). Transport infrastructure provision and operations: Why should governments choose private-public partnership. Research in Transportation Economics, 38(2013), 122-127.

Deloitte. (2015). Trending P3- The involving role of value for money analysis in supporting project delivery selection. United Kingdom: Deloitte Touche Tohmatsu Limited.

F. Belaid \& D. De Wolf. (2009). Stochastic evaluation of petroleum investment projects using MTCs. Ecole de Gestion de I'University de Liege.

Fitzgerald, P. (2004). Review of Partnerships Victoria Provided Infrastructure: Final Report to the Treasure. Mebourne, Australia: Growth Solutions Group.

Grimsey, D.\& Lewis, M.K. (2005). Are Public Private Partnership Value for money? Evaluating alternative approaches and comparing academic and practitioner view. Accounting Forum, 29(4), 345-378.

Hemming, R. (2006). Public-Private Partnerships, Government Guarantees, and Fiscal Risk. Washington: International Monetary Fund .

HM Treasury. (2006). Value for money guidance. London: The Controller of Her Majesty's Stationery office.

IMF. (2009, July). The Effects of the Financial Crisis on Public-Private Partnerships. International Monetary Fund. Retrieved June 20, 2016, from International Moneytary Fund - : https://www.imf.org/external/pubs/ft/wp/2009/ wp09144.pdf

Infrastructure Ontario. (2007). Assessing value for money - A guide to infrastructure Ontario’s methodology. Ontario: (C) Queen's Printer for Ontario.

KDI. (2010). Detailed guideline for value for money test for build-transfer-operate (BOT) Public-private partnership (PPP) projects. . Korea Development Institute. Public and Private Infrastructure Investment Management Center.

Kile, J. (2014). Public-Private Partnerships for Highway projects. United State: Congressional Budget Office. Retrieved December 12, 2014, from https:/www.cbo.gov/sites/default/files/113th-congress-2013-2014/reports/45157-PublicPrivatePartnerships.pdf

Malini, E. (1997). Evaluation of financial viability of BOT transport infrastructure projects. Journal of Indian Road Congress, 58(1), 87-123.

National Council for Public-Private Partnerships. (2012). Testing Tradition - Assessing the added value of public private partnerships. Arlington, VA: National Council for Public-Private Partnerships.

Park, K. A. (2007). A comparative analysis of PSC and PFI for Cost-effective Solution for SewageTreatment Facilities. Seoul: diss., Seoul National University.

Partnership Victoria. (2003). Use of Discount Rates in the Partnerships Victoria Process. Victoria: Technical Note. 
Sarmanto, J. M. (2010). Do public-private partnerships create value for money for the public sector? The Portuguese experience. OECD Journal on Budgetting, 2010(1), 93-119.

Shaoul, J. (2005). A critical financial analysis of the private initiative: Selecting a financing method allocating economic wealth. Critical perspective on Accounting, 16(4), 441-471.

Takim, R., Ismal, K., Nawawi, A.H. and Jaafar, A. (2009, March). The Malaysian private finance initiative and value for money. Asian social science, 5(3), 103-111.

Tsukada, S. (2015). Adoption of shadow bid pricing for enhanced application of "value for money" methodology to PPP programs. Public Works Management and Policy, 20(3), 248-263.

World Bank. (2013). Value-for-Money Analysis Practices and Challenges: How Governments Choose When to Use PPP to Deliver Public Infrastructure and Services. Report from World Bank Global Round-Table. Retrieved March 15, 2016, from World Bank: http://www.ppiaf.org/sites/ppiaf.org/files/publication/VFM.pdf

World Bank. (Sep, 2013). Assessment of financing framework for municipal infrastructure. Washington, DC: The World Bank.

Zhen Hu \& Shu Chen. (2014). Value for money and its influential factors: an empirical study of PPP projects in Japan. Built Environment Project and Asset Management, 4(2), 166-179. doi:10.1108/BEPAM-12-2012-0055 